Case Report

\title{
De Novo Postinfectious Glomerulonephritis Secondary to Nephritogenic Streptococci as the Cause of Transplant Acute Kidney Injury: A Case Report and Review of the Literature
}

\author{
Alexander Bullen (iD) and Mita M. Shah \\ Division of Nephrology-Hypertension, University of California San Diego, San Diego, CA, USA \\ Correspondence should be addressed to Mita M. Shah; mshah@ucsd.edu
}

Received 22 December 2017; Accepted 26 April 2018; Published 31 May 2018

Academic Editor: Ryszard Grenda

Copyright (C) 2018 Alexander Bullen and Mita M. Shah. This is an open access article distributed under the Creative Commons Attribution License, which permits unrestricted use, distribution, and reproduction in any medium, provided the original work is properly cited.

\begin{abstract}
Acute kidney injury is common among kidney transplant recipients. Postinfectious glomerulonephritis secondary to nephritogenic streptococci is one of the oldest known etiologies of acute kidney injury in native kidneys but rarely reported among kidney transplant recipients. This report is of a biopsy-proven case of acute kidney injury in a renal allograft recipient caused by de novo poststreptococcal glomerulonephritis.
\end{abstract}

\section{Introduction}

Acute kidney injury (AKI) is common in kidney transplant recipients (KTR) [1] and it has been identified as a risk factor for graft failure $[1,2]$ and death with a functioning transplant [2]. Postinfectious glomerulonephritis (PIGN) secondary to nephritogenic streptococci is a well-recognized cause of native kidney AKI. In a seminal paper in 1812, Wells detailed the complications of scarlet fever and described this glomerulonephritis as the "dropsy that follows scarlet fever" [3]. He noted that it mainly occurred in children, approximately three weeks after a mild fever and it consisted of edema starting in the face, decreased urine output, red urine, nausea, and vomiting, which would "recede after no long stay" [3].

PIGN secondary to nephritogenic streptococci has a heterogeneous clinical presentation ranging from asymptomatic to nephrotic syndrome [4]. Diagnosis is based on clinical findings in addition to documentation of a recent GAS infection by positive throat or skin culture or serologic tests, such as anti-streptolysin O (ASO) antibodies [5].

Few reports of PIGN secondary to nephritogenic streptococci as the cause of AKI in KTR are currently available in the literature. We present a biopsy-proven rare cause of AKI in a KTR as PIGN secondary to nephritogenic streptococci.

\section{Case Presentation}

The patient was a 45-year-old Hispanic male who had endstage renal disease of unknown etiology, hypertension, and hyperlipidemia. His HLA typing was A 2,- B 7, 35, Cw 4, 7, DR 4,- DQ 8,-. His donor was a 46-year-old Hispanic female with history of hyperlipidemia with a measured 24hour urine creatinine clearance of $151 \mathrm{ml} / \mathrm{min}$. Her HLA typing was A 2,31, B 35,44, Cw 4,5, DR 4,-, DQ 7,8. The patient had been on intermittent hemodialysis for two years prior to undergoing living related kidney transplant. Induction therapy consisted of basiliximab and solumedrol. Maintenance therapy was with tacrolimus, mycophenolate mofetil, and prednisone. His two-year course after transplant had been unremarkable, with a baseline serum creatinine of $1.5-1.7 \mathrm{mg} / \mathrm{dL}(134-150 \mu \mathrm{mol} / \mathrm{L})$, without proteinuria or hematuria.

Two years after transplant he presented to the renal transplant clinic with complaints of lower extremity edema that had appeared over the previous three days. He stated he had experienced a flu-like illness a week prior. In addition, he admitted to inadvertently taking tacrolimus $1 \mathrm{mg}$ q12h, rather than his prescribed dose of $3 \mathrm{mg}$ twice a day for almost one month. He had corrected the dose approximately 3 weeks prior to presentation. On examination, he was normotensive 


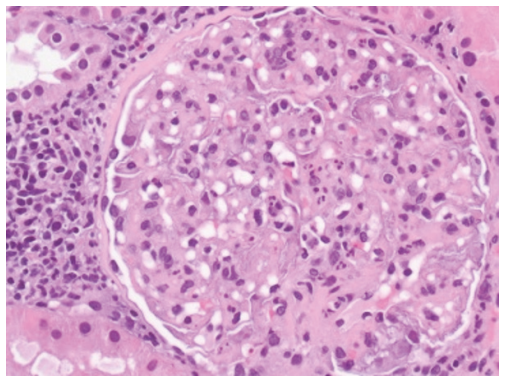

(a)

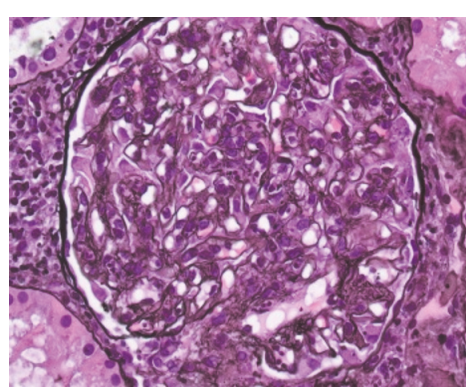

(b)

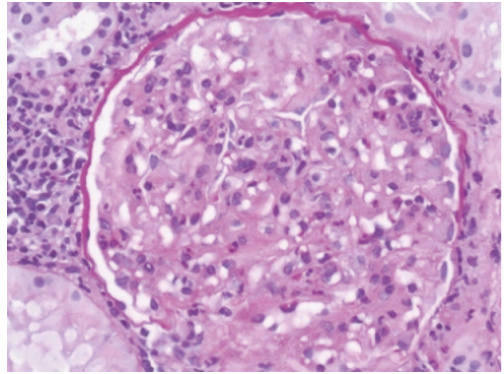

(c)

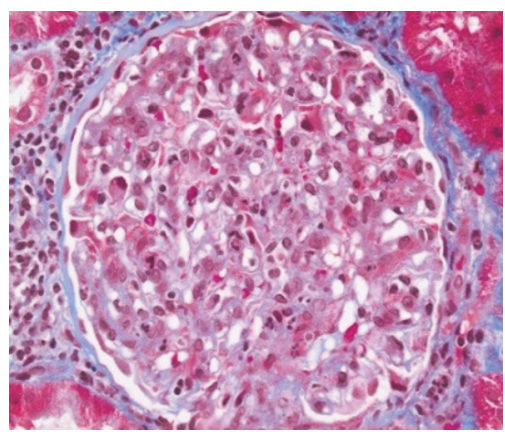

(d)

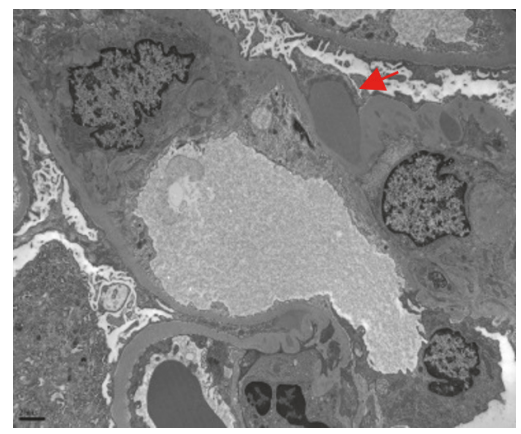

(e)

FIGURE 1: (a) Light microscopy. Hematoxylin and stain. Significant endocapillary proliferation with neutrophils and swollen endothelial cells. (b) Jones stain with occasional double contour. No evidence of significant crescents noted. (c) Periodic acid-Schiff stain revealed mild mixed interstitial inflammation with lymphocytes, plasma cells, and neutrophils. (d) Trichrome stain with focal mild interstitial fibrosis and tubular atrophy. (e) Electron microscopy. Large subepithelial electron dense deposits (arrow) consistent with "humps".

and afebrile. Cardiovascular and respiratory examinations were normal. He had periorbital edema and $6 \mathrm{~mm}$ pitting edema in lower extremities. He did not have graft tenderness or bruit.

Laboratory data was remarkable for creatinine of $2.2 \mathrm{mg} / \mathrm{dL} \quad(194 \mu \mathrm{mol} / \mathrm{L})$. Urinalysis showed moderate blood and $3+$ protein (previously no proteinuria), urinary sediment of more than 50 red blood cells (RBCs), 11-20 white blood cells (WBCs) per high power field (HPF), and urine protein/creatinine ratio of $8.2 \mathrm{~g}$ (previously $100 \mathrm{mg}$ ). Tacrolimus trough was $4.9 \mathrm{ng} / \mathrm{mL}$.

Due to acute kidney injury, proteinuria, and hematuria in the setting of suboptimal immunosuppression, there was a high concern for acute rejection versus rapidly progressive glomerulonephritis perhaps due to recurrence of the unknown primary disease. Renal ultrasound and a renal biopsy were ordered. Given the risk of acute rejection due to inadvertent medication noncompliance, prednisone was increased from $10 \mathrm{mg}$ daily to $50 \mathrm{mg}$ daily, tacrolimus was increased from $3 \mathrm{mg}$ twice a day to $5 \mathrm{mg}$ twice a day, and mycophenolate mofetil was increased to $1500 \mathrm{mg}$ twice a day. Of note, $\mathrm{BK}$ virus and donor specific antibodies were negative a month prior.

The renal US was negative for hydronephrosis or calculi. Three days later, a biopsy was performed.

Preliminary biopsy report was consistent with postinfectious glomerulonephritis (Figure 1). Due to the recent infection, anti-streptolysin O (ASO) antibodies, C3, and C4 were ordered. Since initial biopsy did not have any glomeruli for immunofluorescence (IF), he was scheduled for repeat biopsy.

In the interim, $\mathrm{C} 3$ and $\mathrm{C} 4$ were reported. $\mathrm{C} 3$ was low at $59 \mathrm{mg} / \mathrm{dL}$ with a normal C4 at $35 \mathrm{mg} / \mathrm{dL}$ (Table 1). Tacrolimus trough was $8.6 \mathrm{ng} / \mathrm{mL}$.

Second kidney biopsy one week later revealed minimal residual subendothelial electron dense deposits, but no evidence of large subepithelial electron dense deposits (Figure 2). IF showed nonspecific patchy staining with C3 in glomeruli and some tubules. All other reagents were negative, including $\mathrm{C} 4 \mathrm{~d}$ in peritubular capillaries, BK, and SV40 in tubular cells. There is no evidence of cellmediated or antibody mediated glomerulonephritis. Overall, biopsy was consistent with resolving postinfectious glomerulonephritis. Anti-streptolysin O (ASO) was elevated at $603 \mathrm{IU} / \mathrm{mL}$ (Table 1), highly indicative of Streptococcus being the causative agent.

Given that his AKI did not appear to be due to rejection, tacrolimus was decreased back to his basal dose of $3 \mathrm{mg}$ twice a day and prednisone was tapered to $10 \mathrm{mg}$ daily. Fluid management was achieved with furosemide. He was not prescribed any antibiotics. A month later, creatinine had decreased to $1.9 \mathrm{mg} / \mathrm{dL}(168 \mu \mathrm{mol} / \mathrm{L})$, and in a 3-month period, it had returned to baseline and proteinuria and hematuria had completely resolved (Figure 3 and Table 1).

\section{Discussion}

AKI is common in renal allograft recipients [1] due to multiple risk factors including single kidney, use of calcineurin 
TABLE 1: Laboratory parameters during clinical course.

\begin{tabular}{|c|c|c|c|c|c|c|c|}
\hline Day & 0 & 1 & 5 & 10 & 15 & 55 & 85 \\
\hline Creatinine $(\mathrm{mg} / \mathrm{dL})$ & 1.6 & 2.2 & 2.1 & 2.3 & 1.9 & 1.8 & 1.7 \\
\hline Protein/creat ratio & 0.1 & 8.3 & 4.4 & 2 & 1.6 & 0.4 & 0.2 \\
\hline Urine RBCs & $0-2$ & $0-2$ & $>50$ & $21-50$ & $11-20$ & $11-20$ & $0-2$ \\
\hline Urine WBCs & $0-2$ & $0-2$ & $11-20$ & $11-20$ & $11-20$ & $3-5$ & $0-2$ \\
\hline $\mathrm{C} 3(\mathrm{mg} / \mathrm{dL})^{*}$ & & & 59 & & 93 & & 146 \\
\hline $\mathrm{C} 4(\mathrm{mg} / \mathrm{dL})^{* *}$ & & & 34 & & 36 & & 42 \\
\hline ASO $\mathrm{Ab}^{* * *}$ & & & 603 & & & & 359 \\
\hline
\end{tabular}

${ }^{*} \mathrm{C} 3$ normal range: 90-180; ${ }^{* *} \mathrm{C} 4$ normal range: $10-40 \mathrm{mg} / \mathrm{dL} ;{ }^{* * *} \mathrm{ASO} \mathrm{Ab}=$ anti-streptolysin $\mathrm{O}$ antibodies.

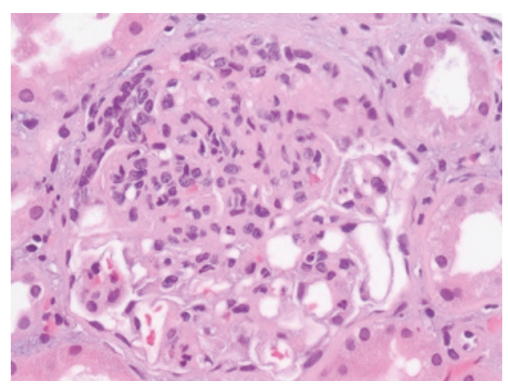

(a)

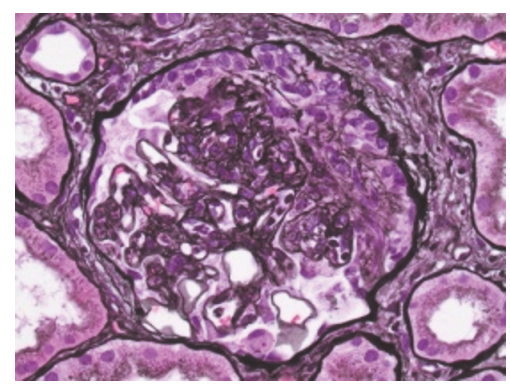

(b)

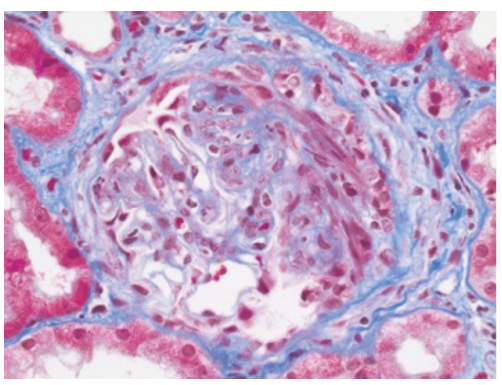

(c)

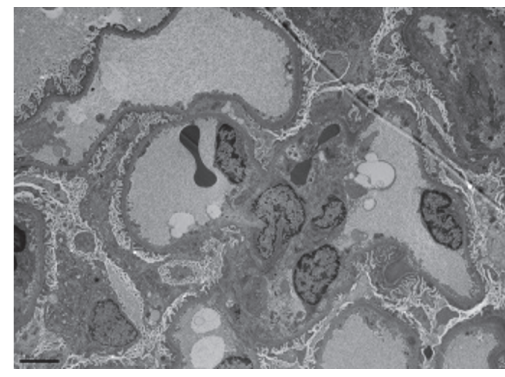

(d)

Figure 2: (a) Light microscopy. Hematoxylin and Eosin stain with decreased endocapillary proliferation of neutrophils with some karyorrhectic debris and moderate crescents. (b) Jones stain with an early fibroepithelial crescent. (c) Trichrome stain with crescent and focal mild interstitial fibrosis and tubular atrophy. (d) Electron microscopy. Minimal residual subendothelial electron dense deposits but no evidence of large subepithelial electron dense deposits "humps".

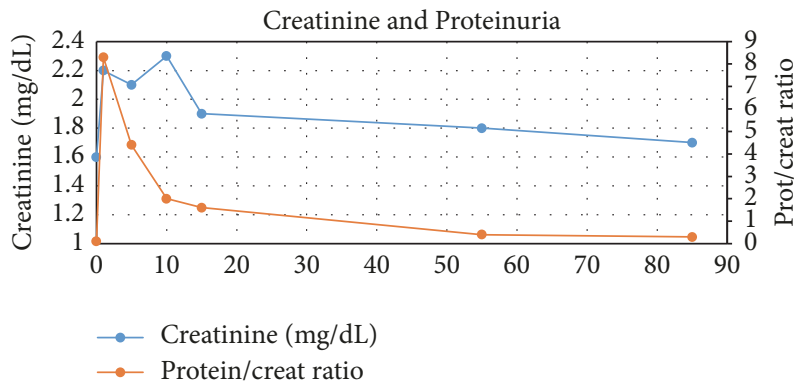

FIGURE 3: Creatinine and spot urine protein/creatinine ratio during clinical course.

inhibitors, and increasing use of marginal donor kidneys, among others. AKI in this population has been identified as a risk factor for graft failure $[1,2]$ and death with a functioning transplant [2]. Infections are the second most common cause of death in kidney transplants recipients due to multiple factors including immunosuppressed status, donor-derived infection, and underlying comorbidities [6]. CMV disease, Epstein-Barr virus infection, and BK polyomavirus infection are among the most common infections in kidney transplant recipients [7]. Glomerular disease because of infection has been described in KTR in the case of cryoglobulinemic and noncryoglobulinemic membranoproliferative GN secondary to hepatitis C; however, there are only seven reported cases of postinfectious glomerulonephritis [8], with only one reported case to our knowledge of poststreptococcal glomerulonephritis occurring in a pediatric transplant recipient [9]. Three cases were due to Staphylococcus aureus, none of which had recovery of their graft function and one died.

PIGN secondary to nephritogenic streptococci is caused by nephritogenic strains of group A beta-hemolytic Streptococcus, which cause skin and throat infections. Two of the primary antigens are the nephritis-associated plasmin 
receptor (NAPIr) [10] and the streptococcal pyrogenic exotoxin B (SPEB) [11]. They both activate the alternative complement pathway [12]. The plasmin-binding capacity of NAPIr plays a key role in the immune complex deposition and local inflammation [13]. SPEB is found in the subepithelial electron dense deposits (humps) which are a characteristic finding of this disease [14]. Over thirty years ago, HLA-DRw4 was found to be associated with increased susceptibility to poststreptococcal glomerulonephritis [15]. Currently, genomics studies with microarray technology and proteomic analysis are being performed to better understand GAS pathogenesis and thus develop targeted therapies [16].

Although poststreptococcal glomerulonephritis is typically thought of as a disease affecting children, it has a bimodal distribution, also affecting patients older than 60 years of age. The clinical spectrum is varied, ranging from asymptomatic disease with microscopic hematuria to acute nephritic syndrome. Patients develop nephrotic range proteinuria, edema, and acute kidney injury. Laboratory studies reveal low $\mathrm{C} 3$ and $\mathrm{CH} 50$ early in the disease course with typically normal C4 $[17,18]$. Nonetheless, there are some cases with low C4, suggestive of activation of classical pathway as well [19].

Some have postulated that PIGN is a self-limiting form of C3 glomerulopathy [20], based on the presence of low levels of C3. However, it is important to denote some key differences between the two diseases. First, in accordance with the hypothesis that C3 glomerulopathy is secondary to an abnormality in the alternative complement pathway, there is bright C3 staining and lack of significant immunoglobulin staining, whereas in PIGN there is bright staining of both C3 and IgG [21]. It is important to note that there are the so called cases of "atypical" PIGN, in which the IgG may not be present in the IF and clinically, there is persistent hematuria and proteinuria and sometimes progression to end-stage renal disease. When Sethi et al. evaluated eleven of such cases; they found an abnormality in the alternative pathway, leading them to speculate that those cases represented undiagnosed C3 glomerulonephritis [22]. Another key difference is found in the electron microscopy where in C3 glomerulopathy, there are mesangial, subendothelial, or sometimes subepithelial or intramembranous deposits which are lobular and amorphous [21]. However, in PIGN, one typically finds clearly demarcated subepithelial humps. Furthermore, C3 glomerulopathy tends to be a progressive disease [23] and it is known to recur in transplant kidneys $[24,25]$ and in the patient described in this case, the $\mathrm{C} 3$ levels returned to normal and he has remained with stable renal function without proteinuria, hematuria, or hypocomplementemia for the past five years. Certainly, as the C3 glomerulopathy consensus report noted in 2013 [26] and the study from Sethi et al. suggests [22], further investigation for C3 glomerulopathy is warranted if any atypical clinical or histological features are present.

De novo acute postinfectious glomerulonephritis is not a commonly reported etiology of AKI in KTRs, but in the few cases that have been reported, some peculiarities have been noted [8]. First, a heterogeneous etiology of bacterial, fungal, viral, and parasitic infections triggering an acute glomerulonephritis is sometimes seen in transplant patients. Second, when the glomerulonephritis was triggered by etiologies other than Streptococcus, such as Staphylococcus and E. coli, the most common urinary pathogen in KTRs [9], patients required renal replacement therapy. Interestingly, of the three cases described by Moroni et al., none were caused by Streptococcus. Plumb et al. also reported three cases of PIGN caused by $S$. aureus, CMV infection, and a presumed urinary tract infection [27]. It is important to note that all the cases they reported of PIGN were in patients with type $1 \mathrm{DM}$, leading to the speculation that these patients may be at higher risk of developing this glomerular disease as others have suggested [28]. None of the cases that Plumb et al. reported were caused by nephritogenic streptococci. To our knowledge there is only one other case of posttransplant acute PIGN secondary to nephritogenic streptococci in the literature and it was in a 12-year-old male, 1 year after receiving a transplant [9].

Treatment for this disease is mainly supportive, although methylprednisolone and even plasmapheresis have been used, especially when caused by $S$. aureus and E. coli $[19,29]$. Unfortunately, of the seven cumulative cases reviewed by Moroni et al., four ultimately were restarted on dialysis and one died [8], illustrating the severity of this disease.

\section{Conclusions}

This case reveals the importance of having a prompt and thorough evaluation of acute kidney injury. Although the most common etiologies of AKI in KTRs are calcineurin inhibitor toxicity, recurrence of the primary disease, and acute rejection, relatively uncommon entities such as PIGN secondary to nephritogenic streptococci may cause acute kidney injury.

\section{Conflicts of Interest}

The authors declare that there are no conflicts of interest regarding the publication of this paper.

\section{Acknowledgments}

Dr. Alexander Bullen was supported by a Ruth L. Kirschstein training grant from the National Institute of Diabetes and Digestive and Kidney Diseases (NIDDK; T32DK104717).

\section{References}

[1] M. Nakamura, G. Seki, K. Iwadoh et al., "Acute kidney injury as defined by the RIFLE criteria is a risk factor for kidney transplant graft failure," Clinical Transplantation, vol. 26, no. 4, pp. 520-528, 2012.

[2] A. Mehrotra, C. Rose, N. Pannu, J. Gill, M. Tonelli, and J. S. Gill, "Incidence and consequences of acute kidney injury in kidney transplant recipients," American Journal of Kidney Diseases, vol. 59, no. 4, pp. 558-565, 2012.

[3] W. C. Wells, "Observations on the dropsy which succeeds scarlet fever," Transactions of a Society for the Improvement of Medical and Chirurgical Knowledge, vol. 3, pp. 167-186, 1812. 
[4] J. E. Lewy, L. Salinas-Madrigal, P. B Herdson, C. L. Pirani, and J. Metcoff, "Clinico-pathologic correlations in acute poststreptococcal glomerulonephritis. A correlation between renal functions, morphologic damage and clinical course of 46 children with acute poststreptococcal glomerulonephritis," Medicine, vol. 50, no. 6, pp. 453-501, 1971.

[5] T. M. Eison, B. H. Ault, D. P. Jones, R. W. Chesney, and R. J. Wyatt, "Post-streptococcal acute glomerulonephritis in children: clinical features and pathogenesis," Pediatric Nephrology, vol. 26, no. 2, pp. 165-180, 2011.

[6] K. S. Ko, D. O. Cho, and J. H. Ahn, "Infections after renal transplantation," Transplantation proceedings, vol. 26, no. 4, pp. 20722074, 1994.

[7] S. Karuthu and E. A. Blumberg, "Common infections in kidney transplant recipients." Clinical journal of the American Society of Nephrology: CJASN, vol. 7, no. 12, pp. 2058-2070, 2012.

[8] G. Moroni, D. Papaccioli, G. Banfi, A. Tarantino, and C. Ponticelli, "Acute Post-Bacterial Glomerulonephritis in Renal Transplant Patients: Description of Three Cases and Review of the Literature," American Journal of Transplantation, vol. 4, no. 1, pp. 132-136, 2004.

[9] J. M. Sorof, N. Weidner, D. Potter, and A. A. Portalel, "Acute post-streptococcal glomerulonephritis in a renal allograft," Pediatric Nephrology, vol. 9, no. 3, pp. 317-319, 1995.

[10] N. Yoshizawa, K. Yamakami, M. Fujino et al., "Nephritisassociated plasmin receptor and acute poststreptococcal glomerulonephritis: Characterization of the antigen and associated immune response," Journal of the American Society of Nephrology, vol. 15, no. 7, pp. 1785-1793, 2004.

[11] G. Parra, B. Rodríguez-Iturbe, S. Batsford et al., "Antibody to streptococcal zymogen in the serum of patients with acute glomerulonephritis: A multicentric study," Kidney International, vol. 54, no. 2, pp. 509-517, 1998.

[12] B. Rodríguez-Iturbe and S. Batsford, "Pathogenesis of poststreptococcal glomerulonephritis a century after Clemens von Pirquet," Kidney International, vol. 71, no. 11, pp. 1094-1104, 2007.

[13] T. Oda, K. Yamakami, F. Omasu et al., "Glomerular plasminlike activity in relation to nephritis-associated plasmin receptor in acute poststreptococcal glomerulonephritis," Journal of the American Society of Nephrology, vol. 16, no. 1, pp. 247-254, 2005.

[14] B. Rodriguez-Iturbe and J. M. Musser, "The current state of poststreptococcal glomerulonephritis," Journal of the American Society of Nephrology, vol. 19, no. 10, pp. 1855-1864, 2008.

[15] Z. Layrisse, B. Rodríguez-Iturbe, R. García-Ramírez, A. Rodríguez, and J. Tiwari, "Family studies of the HLA system in acute post-streptococcal glomerulonephritis," Human Immunology, vol. 7, no. 3, pp. 177-185, 1983.

[16] A. H. Tart, M. J. Walker, and J. M. Musser, "New understanding of the group A Streptococcus pathogenesis cycle," Trends in Microbiology, vol. 15, no. 7, pp. 318-325, 2007.

[17] E. J. Lewis, C. B. Carpenter, and P. H. Schur, "Serum complement component levels in human glomerulonephritis." Annals of Internal Medicine, vol. 75, no. 4, pp. 555-560, 1971.

[18] J. S. Cameron, R. M. Vick, C. S. Ogg, W. M. Seymour, C. Chantler, and D. R. Turner, "Plasma C3 and C4 Concentrations in Management of Glomerulonephritis," British Medical Journal, vol. 3, no. 5882, pp. 668-672, 1973.

[19] R. J. Wyatt, J. Forristal, C. D. West, S. Sugimoto, and J. G. Curd, "Complement profiles in acute post-streptococcal glomerulonephritis," Pediatric Nephrology, vol. 2, no. 2, pp. 219-223, 1988.
[20] H. T. Cook, “C3 glomerulopathy," F1000Research, vol. 6, article no. $248,2017$.

[21] Fervenza FCSS. Clinical presentation, classification, and causes of membranoproliferative glomerulonephritis, https://www.uptodate.com/contents/clinical-presentation-classification-and-causes-of-membranoproliferative-glomerulonephritis.

[22] S. Sethi, F. C. Fervenza, Y. Zhang et al., "Atypical postinfectious glomerulonephritis is associated with abnormalities in the alternative pathway of complement," Kidney International, vol. 83, no. 2, pp. 293-299, 2013.

[23] A. Servais, L.-H. Noël, L. T. Roumenina et al., "Acquired and genetic complement abnormalities play a critical role in dense deposit disease and other C3 glomerulopathies," Kidney International, vol. 82, no. 4, pp. 454-464, 2012.

[24] M. D. Denton and A. K. Singh, "Recurrent and de novo glomerulonephritis in the renal allograft," Seminars in Nephrology, vol. 20, no. 2, pp. 164-175, 2000.

[25] J. Floege, "Recurrent glomerulonephritis following renal transplantation: An update," Nephrology Dialysis Transplantation, vol. 18, no. 7, pp. 1260-1265, 2003.

[26] M. C. Pickering, V. D. D’agati, C. M. Nester et al., "C3 glomerulopathy: consensus report," Kidney International, vol. 84, no. 6, pp. 1079-1089, 2013.

[27] T. J. Plumb, A. Greenberg, S. R. Smith et al., "Postinfectious glomerulonephritis in renal allograft recipients," Transplantation, vol. 82, no. 9, pp. 1224-1228, 2006.

[28] S. H. Nasr, G. S. Markowitz, J. D. Whelan et al., "IgA-Dominant Acute Poststaphylococcal Glomerulonephritis Complicating Diabetic Nephropathy,' Human Pathology, vol. 34, no. 12, pp. $1235-1241,2003$.

[29] H. G. Nebeker, G. Hercz, G. K. Feld, T. M. Stanley, J. W. Coburn, and K. Kurokawa, "Postinfectious glomerulonephritis in a renal allograft associated with a mycotic aneurysm of a coronary artery," American Journal of Medicine, vol. 76, no. 5, pp. 940942, 1984. 


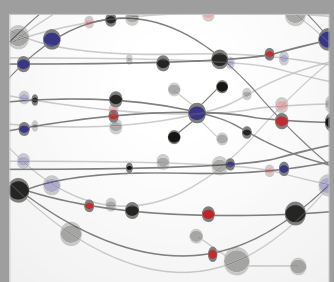

The Scientific World Journal
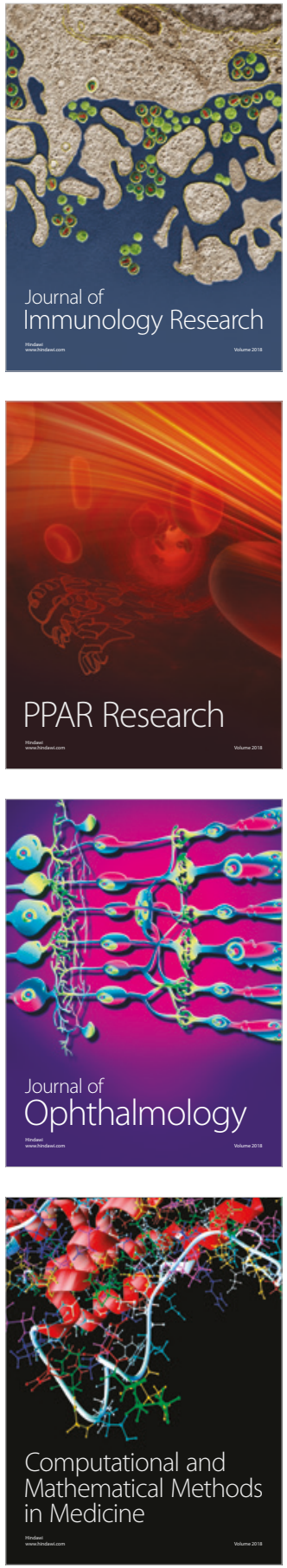

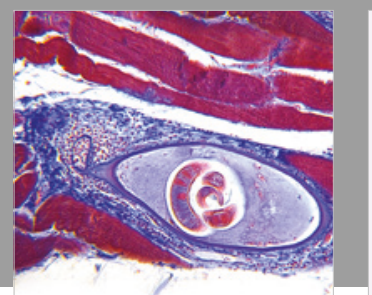

Gastroenterology Research and Practice

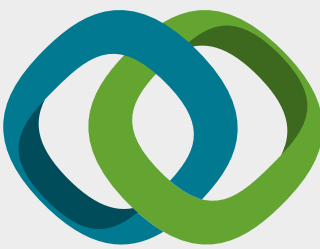

\section{Hindawi}

Submit your manuscripts at

www.hindawi.com
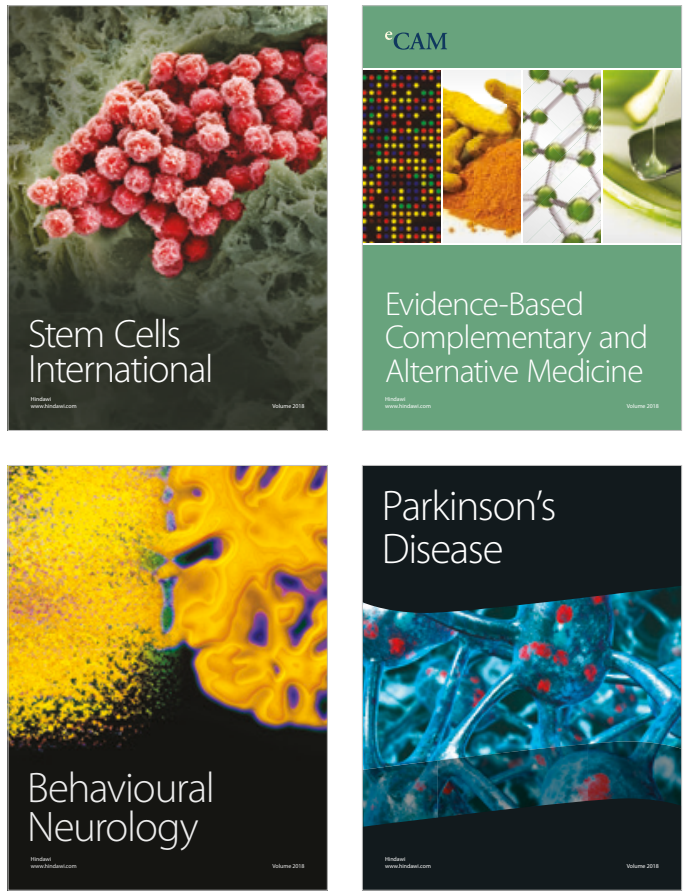

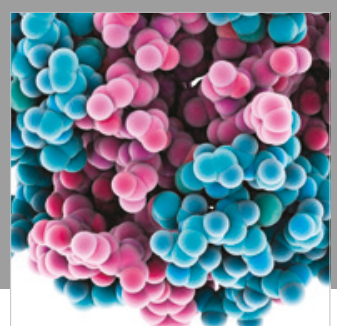

ournal of

Diabetes Research

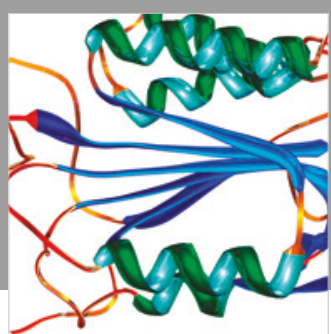

Disease Markers
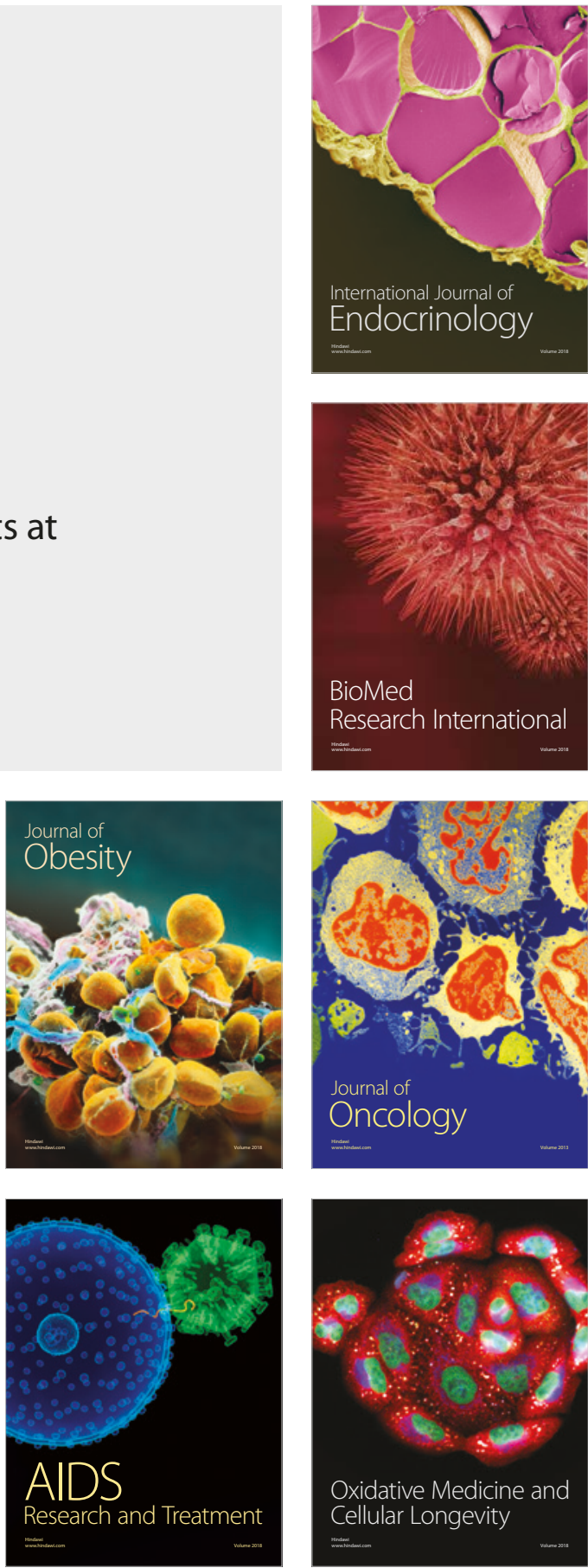